УДК 327

DOI: http://dx.doi.org/10.15211/vestnikieran220218592

\title{
Алексей ЧИХАЧЕВ
}

\section{«ЕВРОПЕЙСКИЙ ПОВОРОТ» В ВОЕННОМ ЭКСПОРТЕ ФРАНЦИИ}

\begin{abstract}
Аннотация. В статье анализируется новая тенденция в политике экспорта вооружений современной Франции - повышение доли европейских стран в географической структуре продаж. С опорой на статистические данные и примеры отдельных сделок приведены региональные приоритеты франиузского экспорта до президентства Э. Макрона, выявлены причины поворота в сторону Европы на современном этапе и обозначены его возможные предельы. Автор обрашает внимание, что до недавнего времени ключевыми военно-техническими партнёрами Парижа были государства Ближнего Востока и Азии, обеспечивщие $2 / 3$ международного спроса на продукиию ВПК Пятой Республики. Однако сегодня их роль снижается в пользу стран ЕС: Бельгии, Румынии, Греции и др., с которыми Париж в 2018-2021 г2. подписал серию крупных контрактов. Подобное развитие событий объясняется, прежде всего, непростым внешнеполитическим контекстом, вынуждаюшим членов Евросоюза выделять больше средств на нужды обороны, а также временными затруднениями в отношениях Франции с ближневосточными клиентами. В конечном итоге автор приходит к выводу, что усилия по «европеизаџии» продаж, по всей видимости, будут продолжаться, но говорить об окончательном переходе франиузского экспорта в Европу ещё слишком рано. Более реалистичная задача, которую де-факто решает Париж, - сбалансировать портфель заказов, разнообразив круг покупателей.
\end{abstract}

Ключевые слова: Франщия, Европейский союз, Ближний Восток, экспорт вооружений, военно-техническое сотрудничество, Эммануэль Макрон.

Одним из двух традиционных направлений работы оборонной промышленности Франции является, наряду с выполнением госзаказа, продажа вооружений зарубежным странам. Согласно данным Министерства вооружённых сил, поставки техники иностранным покупателям приносят более трети от всех доходов ВПК Пятой Республики ${ }^{1}$, а также обеспечивают $10 \%$ от товарного экспорта Франции (на конец 2019 г.) $)^{2}$, положительно влияя на торговый баланс страны. Сегодня в военной индустрии задействовано порядка 200 тыс. человек преимущественно высокой квалификации и функционирует 4 тыс. фирм различного масштаба ${ }^{3}$ : международные контракты помогают поддерживать эту систему, сохраняя рабочие места и технологии. По наблюдению французских экспертов, работа по долгосрочным соглашениям с внешними импортёрами сыграла существенную роль в том, что национальный ВПК ныне проходит через коронакризис с меньшими потерями по сравнению с гражданскими отрасля-

\footnotetext{
(C) Чихачев Алексей Юрьевич - кандидат политических наук, преподаватель Санкт-Петербургского государственного университета. Aдpec: 199034, Россия, Санкт-Петербург, Университетская наб., д. 7/9. E-mail: alexchikhachev@gmail.com.
}

Статья поступила в редакиию: 16.02.2021.

${ }^{1}$ Rapport au Parlement sur les exportations d'armement de la France. 2018. P. 10.

${ }_{3}^{2}$ Actualisation stratégique 2021. P. 42.

${ }^{3}$ Ibid. 
ми, сумев избежать масштабного сокращения своей деятельности ${ }^{1}$

Последним на данный момент крупным успехом военного экспорта Франции стало новое соглашение с Грецией (январь 2021 г.): Париж поставит Афинам 18 истребителей Rafale и соответствующее ракетное вооружение, а также возьмёт на себя обучение экипажей и первоначальное техническое обслуживание. По предварительным данным, стоимость контракта оценивается в 2,5 млрд евро, что позволяет говорить о нём как об одной из самых крупных сделок французского ВПК за последние несколько лет. Комментируя факт подписания соглашения, министр вооружённых сил Пятой Республики Ф. Парли напомнила о необходимости укрепления европейской обороны с опорой на собственные возможности стран ЕС и заметила, что Греция выступила первым государством Евросоюза, закупившим этот самолёт².

Представляется, что активизируя военное партнёрство с греческой стороной, правительство Франции руководствуется тактическими соображениями, будь то поддержка Афин на фоне растущих противоречий с Турцией или поиск дополнительных источников дохода для авиастроительной отрасли. Однако проевропейский акцент, сделанный министром, также не случаен, поскольку новое соглашение вписывается в более широкую тенденцию, наметившуюся при президенте Э. Макроне, - переориентацию французского военного экспорта на европейских покупателей. По данным оборонного ведомства за 2019 г., на страны ЕС приходится более $40 \%$ от общей стоимости новых зарубежных заказов ВПК Франции ${ }^{3}$, что превышает их обычную долю в несколько раз. Так, помимо Греции, за 2018-2020 гг. уже удалось развить сотрудничество, в частности, с:

- Бельгией (продажа и дальнейшее техобслуживание 60 бронеавтомобилей Jaguar и 382 Griffon за 1,6 млрд евро);

- Румынией (4 корвета типа Gowind за 1,2 млрд со строительством на румынских верфях);

- Испанией (23 вертолёта NH9O от европейской группы NHIndustries с французским участием, 1,4 млрд);

- Венгрией (36 вертолётов H225M и H145M)

С учётом данных примеров целесообразно изучить нынешнюю французскую политику экспорта вооружений несколько подробнее: какие приоритеты в продажах наблюдались до прихода нынешнего руководства, какие причины легли в основу осуществляемого «поворота» и насколько серьёзные перспективы он имеет.

\section{Стартовые позиции: южноазиатско-ближневосточный крен}

Говоря о сегодняшней «европеизации» французского экспорта вооружений, следует напомнить, что до недавнего времени европейские страны отнюдь не преобладали среди импортёров ВПК Пятой Республики. Как заметила эксперт Л. Беро-Сюдро, в 1961-1990 гг. доля Европы в географической структуре военного экспорта Франции составила только $27 \% 5$. Разовый всплеск наблюдался в течение 1970-1980-х гг. со стороны государств Южной Европы, что хронологически совпало с их переходом к демократическим режимам и вступлением в ЕЭС. Однако экспортная политика Парижа, как правило, оставалась диверсифицированной и

\footnotetext{
1 Armement: une industrie qui ne connait pas la crise. France Culture. 29.01.2021. URL: https://www.franceculture.fr/emissions/entendez-vous-leco/entendez-vous-leco-emission-du-vendredi-29-janvier-2021 (дата обращения 25.03.2021).

Allocution de Florence Parly, signature du contrat Rafale Grèce à Athènes, le 25 janvier 2021.

${ }^{3}$ Rapport au Parlement sur les exportations d'armement de la France. 2020. P. 3.

${ }_{5}^{4}$ Обобщено автором на основе материалов прессы и министерских отчётов.

5 Béraud-Sudreau L. La politique française de soutien à l'export de défense. Raisons et limites d'un succès. Focus stratégique. №73. 2017. P. 16, 21.
}

Научно-аналитический вестник ИЕ РАН, 2021, №2 
не зацикливалась исключительно на ближайших соседях, активно работая в других регионах, в том числе на Ближнем Востоке (31\%), в Африке (17\%), Азии и Океании (12\%), Южной Америке $(10 \%)^{1}$. В значительной степени это объяснялось системными ограничениями биполярной конфронтации - невозможностью на равных конкурировать с американской оборонной промышленностью в Европе. После же окончания холодной войны желание большинства европейских государств экономить оборонные бюджеты также не способствовало их интересу к французским вооружениям, из-за чего роль Европы в структуре экспорта сократилась к середине 2000 -х гг. до $10 \%{ }^{2}$. Поэтому Париж осознанно проводил политику экспорта по другим азимутам, считая продажи техники способом расширения своего политического влияния за пределами континента. В более турбулентных регионах легче проходил поиск покупателей в силу повышенного спроса на военную продукцию, чем Франция пользовалась, последовательно наращивая свой портфель заказов в Саудовской Аравии, Катаре, Ливии, Пакистане и т.д.

На относительно невысоком уровне доля Европы держалась и в течение последнего десятилетия до прихода Э. Макрона к власти: за 2008-2017 гг. в топ-10 покупателей не вошла ни одна европейская страна, кроме Великобритании, но сразу 7 государств Ближнего Востока и Южной/Юго-Восточной Азии ${ }^{3}$. В целом клиенты из данных регионов в те годы обеспечили $69 \%$ военного экспорта Франции ${ }^{4}$. Особенно примечательным стало президентство Ф. Олланда, чья активная экспортная политика позволила Парижу добиться рекордных для себя показателей (совокупной стоимости подписанных контрактов в 2015-2016 гг. на уровне 17 и 14 млрд евро соответственно при средней планке в 6-7 млрд 5 ) за счёт крупных сделок как раз с неевропейскими странами:

- с Египтом, Катаром и Индией были заключены контракты по истребителям Rafale (от 24 до 36 машин);

- с Сингапуром и Кувейтом - соглашения о многоцелевых вертолётах Caracal (16 и 30);

- с Австралией - комплекс долгосрочных договорённостей о строительстве и обслуживании 12 подводных лодок проекта Barracuda.

Первые продажи Rafale потянули вверх весь французский военный экспорт, что позволило Парижу закрепиться на третьем месте после США и России по доле на мировом рынке вооружений $(8 \%)^{6}$. Кроме авиапромышленности, свою клиентуру смогли расширить и другие секторы, в частности, кораблестроение, получившее заказы не только от Австралии на субмарины, но и на фрегаты FREMM и корветы Gowind от Марокко и Египта 7 . Это оказалось возможным в значительной мере потому, что французская военная индустрия традиционно отличается номенклатурным разнообразием и способна самостоятельно производить практически полный спектр техники и оборудования. При Ф. Олланде ставка на разнообразие национальных производств в целом была сохранена, и государство оказало широкую политическую поддержку оборонным компаниям в их экспортных усилиях. Однако задача переориентироваться на Европу ещё не ставилась; основной упор последовал на привычные ближневосточные и азиатские рынки сбыта, что не замедлило принести результат.

С учётом сложившегося положения дел перед следующим президентом сразу же воз-

\footnotetext{
${ }^{1}$ Ibid.

${ }^{2}$ Ibid.

${ }^{3}$ Op. cit. (Rapport ... 2018.). P. 14.

${ }^{4}$ Ibid. P. 15.

${ }_{6}^{5}$ Ibid. P. 14.

6 International Arms Transfers. SIPRI. URL: https://www.sipri.org/research/armament-and-disarmament/arms-andmilitary-expenditure/international-arms-transfers (дата обращения 12.02.2021).

7 Кроме того, Египту в итоге достались два вертолётоносца Mistral, которые Франция отказалась продавать России в 2014 г. в связи с украинским кризисом.
} 
никли две взаимоисключающие задачи. С одной стороны, для поддержания набранных объёмов продаж от правительства и бизнеса требовался поиск всё новых и новых сделок, автоматически предполагавший сохранение приоритета за Ближним Востоком и Южной Азией. С другой стороны, в предвыборной программе Э. Макрона и его Сорбоннской речи (сентябрь 2017 г.) было чётко озвучено стремление к усиленной военно-политической кооперации с членами ЕС, которая неизбежно должна была сказаться и на ориентирах экспортной политики.

\section{Основные причины поворота}

Как показала практика, поначалу в действиях нового руководства превалировал более консервативный подход: в частности, был активирован опцион на покупку Катаром 12 дополнительных истребителей Rafale, а в ОАЭ были законтрактованы 2 новых корвета Gowind. Однако с 2018 г. европейское направление заметно оживилось, что подтверждалось постоянными примерами уже заключённых или вероятных соглашений Парижа то с одной, то с другой страной ЕС (см. выше). Как сформулировала Ф. Парли в одном из отчётов по военному экспорту, Франция «сделала выбор в пользу Европы... Речь идёт о создании партнёрств, поощрении кооперации и совместимости наших армий с волей к совместным действиям. Именно в этом состоит Европа обороны» ${ }^{1}$.

Следует предположить, что на этот выбор повлияло несколько факторов, одновре́менно возникших как в самой Европе, так и в отношениях Франции с её ближневосточными клиентами.

Во-первых, последние события, происходящие по периметру внешних границ Евросоюза, подвели европейцев к мысли о том, что теперь они должны уделить гораздо больше внимания собственной стратегической автономии, чем ранее. Затруднения в трансатлантическом диалоге, напряжённость в отношениях с Россией, нерешённые конфликты в Сирии, Ливии и Сахеле, комплекс противоречий с Турцией - всё это послужило для ЕС и входящих в него стран доказательством распада прежней картины мира, когда вопросы обороны можно было перепоручить заокеанскому союзнику, а самим сосредоточиться на социально-экономических проблемах. На этом негативном фоне, говоря словами Ал.А. Громыко, новое дыхание в последние годы обретает замысел с давней историей - создать собственный политико-военный потенциал ЕС, добиться определённого суверенитета в проведении общей внешней политики и политики безопасности ${ }^{2}$. Получили импульс различные формы оборонно-промышленной кооперации стран Евросоюза, включая Европейский оборонный фонд, программу PESCO, Европейскую инициативу вмешательства (EI2). Франция же, будучи давней сторонницей концепции «Европы-державы», предсказуемо позиционирует себя как лидер этих инициатив и военно-технической интеграции в целом. Экспорт вооружений используется ею как важное проявление солидарности с соседями: пока не начнут давать отдачу три волны проектов PESCO или не будут спроектированы истребитель и танк следующего поколения, Париж предлагает готовые решения уже сейчас.

Во-вторых, благоприятным обстоятельством для переориентации экспорта послужило намерение стран НАТО довести свои оборонные расходы до 2\% ВВП. Европейские государства, не соответствовавшие этой планке, оказались вынуждены заложить дополнительное финансирование на оборону, имея в виду, среди прочего, обновление парка техники. Соответственно, это подогрело спрос на военную продукцию, количественно и качественно разнообра-

\footnotetext{
${ }^{1}$ Op. cit. (Rapport... 2020.). P. 3.

2 Громыко Ал.А. Дилеммы Европейского оборонного союза // Контуры глобальных трансформаций: политика, экономика, право. 2019. Т. 12. №2. С. 8.
}

Научно-аналитический вестник ИЕ РАН, 2021, №2 
зило круг потенциальных сделок, за которые Пятая Республика могла бы соперничать с конкурентами. В сравнении с США, продвигающими интересы своих компаний весьма напористо и нередко сопровождающих военные контракты разнообразными политическими условиями ${ }^{1}$, Франция может восприниматься как более удобный партнёр, стремящийся к гармонизации военно-промышленных комплексов отдельных стран Европы, нежели их размежеванию.

B-третьих, на ближневосточном направлении наблюдается не самая удачная для продаж французских вооружений конъюнктура. Так, ещё в 2017 г. эксперты констатировали сужение неформальных лоббистских возможностей ВПК Франции в Саудовской Аравии из-за возвышения наследного принца М. бин Салмана, к окружению которого французские оружейники не имели достаточных подходов ${ }^{2}$. И действительно, крупных соглашений с Эр-Риядом о тех же Rafale или крупных партиях бронетехники с тех пор так и не появилось, а совокупная стоимость новых сделок с саудовскими клиентами стабилизировалась на уровне менее 1 млрд евро ежегодно ${ }^{3}$. Сократилось взаимопонимание и с Египтом после того, как президент Э. Макрон озвучил А.-Ф. Ас-Сиси ряд претензий в части соблюдения прав человека ${ }^{4}$, несмотря на продолжавшиеся поставки по контрактам 2015-2016 гг. В результате Каир переключился на итальянских поставщиков, согласившись приобрести у тех за 1,2 млрд два фрегата FREMM, изначально предназначавшихся для ВМС Италии (с перспективой заключения пакета дополнительных соглашений по кораблям и истребителям стоимостью ещё в 9-10 млрд) ${ }^{5}$. Кроме того, наложила негативный отпечаток дискуссия о роли ислама во французском обществе, разгоревшаяся во второй половине 2020 г. Экономический бойкот Франции, к которому призывали некоторые мусульманские лидеры, де-факто не состоялся, но ближневосточные государства получили удобный политический предлог, чтобы отказаться от французских поставщиков в пользу более выгодных вариантов (хотя примеров, прямо указывающих на такую логику поведения, пока ещё не наблюдается).

В-четвёртых, тесное сотрудничество с ближневосточными государствами становится поводом для критики французской политики экспорта вооружений за отсутствие должной прозрачности. Неправительственные организации неоднократно замечали, что продаваемые Францией системы используются в уже идущих региональных конфликтах - прежде всего, йеменском, где Саудовская Аравия использует некогда приобретённые у Пятой Республики CAУ CAESAR. Закрывая глаза на конечное применение экспортируемой техники, Париж тем самым нарушает положения Договора ООН о торговле оружием 2014 г., запрещающего поставки вооружений странам - участницам боевых действий. Не менее актуальным является также вопрос об определении стоимости контрактов, невозможности чётко проследить факты коррупции и нецелевого расходования средств. Для исправления ситуации группа депутатов Национального собрания уже предложила существенно расширить парламентский контроль над военными соглашениями, включая создание специальной комиссии, пересмотр гри-

\footnotetext{
1 Зименков Р.И. Политика США в области экспорта вооружений // США и Канада: экономика, политика, культура. 2018. №10. С. 33 .

2 Щегловин Ю.Б. О целях визита президента Франции в Саудовскую Аравию. Институт Ближнего Востока. 16.11.2017. URL: http://www.iimes.ru/?p=39119 (дата обращения 13.02.2021).

${ }^{3}$ Op. cit. (Rapport ... 2020.). P. 111.

4 Conférence de presse conjointe d'Emmanuel Macron et d'Abdel Fattah al-Sisi, Président de la République arabe d' Egypte. Elysee.fr. 28.01.2019. URL: https://www.elysee.fr/emmanuel-macron/2019/01/28/conference-de-presseconjointe-demmanuel-macron-et-dabdel-fattah-al-sissi-president-de-la-republique-arabe-degypte (дата обращения 13.02.2021).

${ }^{5}$ Sforza F., Stabile G. Navi da guerra, elicotteri e caccia: Italia-Egitto, affari per 9 miliardi. La Stampa. 11.02.2020. URL: $\quad$ https://www.lastampa.it/esteri/2020/02/11/news/navi-da-guerra-elicotteri-e-caccia-italia-egitto-affari-per-9miliardi-1.38452055 (дата обращения 24.03.2021).
}

Научно-аналитический вестник ИЕ РАН, 2021, №2 
фов секретности ${ }^{1}$ В докладе не содержалось требования немедленно разорвать все связи с «трудными» клиентами, но рекомендовалось подобрать более строгие критерии для заключения контрактов, соблюдать которые будет априори легче именно на европейском направлении.

\section{Дальнейшие перспективы}

Логичен вопрос: можно ли утверждать, что комбинация указанных факторов привела к долгосрочному изменению французской политики экспорта вооружений, или же переориентация продаж на Европу - лишь временное стечение обстоятельств, наложившееся на подходящий международный контекст? Учитывая подчёркнуто проевропейские убеждения нынешнего руководства Республики, легко предположить, что оно приложит максимум усилий для реализации первого варианта. Акцентированная ставка будет делаться на дальнейшее продвижение Rafale на европейский рынок: кроме Греции, заинтересованность во французском истребителе ныне выражают Финляндия, Хорватия и Швейцария ${ }^{2}$. Однако потенциал для роста есть и за пределами авиастроительного сегмента - прежде всего, за счёт новых бронеавтомобилей Griffon и Jaguar, а также кораблей FREMM и Gowind, предлагаемых той же Греции.

Заметим, что Париж одновре́менно прилагает дипломатические усилия для сближения своей экспортной политики с курсом других европейских стран в данной области. Главным образом, это касается Германии, с которой Париж заключил соответствующее соглашение осенью 2019 г. Необходимость в согласовании позиций выявилась немногим ранее, когда Берлин решил приостановить военное сотрудничество с Саудовской Аравией после убийства Дж. Хашогги, а Франция по этой причине не смогла поставить Эр-Рияду ракеты Meteor с немецкими комплектующими ${ }^{3}$. Теперь же франко-германская договорённость предусматривает, что ни одна из сторон не будет блокировать военный экспорт, если доля её компонентов в конечном продукте менее $20 \%{ }^{4}$. Введение этого правила особо значимо в контексте развития истребителя $F C A S$ и танка $M G C S$, вопрос об экспорте которых также рано или поздно возник бы. Некоторые дополнения последовали и на уровне Евросоюза: так, с сентября 2019 г. по решению Совета ЕС все страны-члены должны активнее обмениваться информацией как о своих текущих продажах, так и о причинах отказов тем или иным покупателям, а также направлять соответствующие отчёты в Европейскую службу внешних связей ${ }^{5}$. В январе 2021 г. был утверждён общий подход к продажам лёгких вооружений, включающий перечень стандартных сведений и обязательств, которые европейские продавцы должны будут запрашивать у своих иностранных клиентов (информацию о конечном пользователе продукции, отсутствии планов на реэкспорт и т.п.) ${ }^{6}$.

\footnotetext{
1 Rapport d'information sur le contrôle des exportations d'armement. Assemblée nationale. 18.11.2020. URL: https://www.assemblee-nationale.fr/dyn/15/rapports/cion_afetr/115b3581_rapport-information\#_Тос256000136 (дата обращения 13.02.2021).

${ }^{2}$ Cabirol M. 2021: la nouvelle année du Rafale à l'exportation? La Tribune. 05.01.2021. URL: https://www.latribune.fr/ entreprises-finance/industrie/aeronautique-defense/2021-la-nouvelle-annee-du-rafale-a-l-exportation-868256.html (дата обращения 14.02.2021).

${ }^{3}$ Сидоров А.С. Франко-германское военно-политическое сотрудничество: «Окно возможностей» или движение по инерции? // Актуальные проблемы Европы. 2019. №4. С. 178-180.

4 Тимофеев П.П., Хорольская М.В. Проектный потенциал франко-германского оборонного сотрудничества // Анализ и прогноз. Журнал ИМЭМО РАН. 2020. №4. С. 70-71. DOI: 10.20542/afij-2020-4-62-75

${ }_{5}$ Council Decision (CFSP) 2019/1560 of 16 September 2019 amending Common Position 2008/944/CFSP defining common rules governing control of exports of military technology and equipment. URL: https://eur-lex.europa.eu/legalcontent/EN/TXT/PDF/?uri=CELEX:32019D1560\&from=GA (дата обращения 24.03.2021).

${ }^{6}$ Council Decision (CFSP) 2021/38 of 15 January 2021 establishing a common approach on the elements of end-user certificates in the context of the export of small arms and light weapons and their ammunition. URL: https://eurlex.europa.eu/legal-content/EN/TXT/PDF/?uri=CELEX:32021D0038\&from=EN (дата обращения 24.03.2021).
}

Научно-аналитический вестник ИЕ РАН, 2021, №2 


$* \quad * \quad *$

Всё же было бы преждевременно говорить о том, что французский военный экспорт уже окончательно переориентировался на Европу. Чтобы превратиться в долгосрочную тенденцию, сформировавшийся при Э. Макроне акцент на ЕС должен, прежде всего, пройти проверку временем и перейти в его вторую президентскую каденцию 2022-2027 гг. (если таковая вообще состоится). Более того, европейский вектор продаж может использоваться Парижем отнюдь не обязательно как замена ближневосточному, но как дополнение к последнему. Об этом говорят продолжающиеся попытки французского ВПК найти новые контракты на Rafale и другую технику в Индии, Индонезии, ОАЭ или Ираке одновре́менно с участием в европейских тендерах ${ }^{1}$. И наоборот, ещё далеко не все страны ЕС готовы полностью следовать в закупках принципу «европейской предпочтительности», о чём вновь говорит опыт Бельгии, выбравшей F-35 вместо Rafale, или государств Восточной Европы. Поэтому фактически Франция стремится к тому, чтобы сделать свою политику военного экспорта более сбалансированной и гибкой: в случае падения продаж на одном направлении уметь компенсировать их ростом на другом. Частичная «европеизация» экспорта помогает достичь этой цели в краткосрочной перспективе, сокращая зависимость французской индустрии от ближневосточных и азиатских клиентов без резкого разрыва с ними. Однако даже при ситуативном повышении доли Европы Ближний Восток и Азия наверняка останутся в числе долгосрочных приоритетов военного экспорта Франции. В этих регионах наибольший интерес у французского ВПК будут вызывать, прежде всего, монархии Персидского залива, Египет и Индия, на рынках которых Париж продолжит конкурировать с США, Россией, своими европейскими партнёрами, а также (в случае Индии) с местными производителями.

\section{Список литературы}

Громыко Ал.А. Дилеммы Европейского оборонного союза // Контуры глобальных трансформаций: политика, экономика, право. 2019. Т. 12. №2. С. 6-28. DOI: 10.23932/2542-02402019-12-2-6-28

Зименков Р.И. Политика США в области экспорта вооружений // США и Канада: экономика, политика, культура. 2018. №10. С. 21-35. DOI: 10.31857/S032120680001073-4

Сидоров А.С. Франко-германское военно-политическое сотрудничество: «Окно возможностей» или движение по инерции? // Актуальные проблемы Европы. 2019. №4. С. 172-186. DOI: $10.31249 / \mathrm{ape} / 2019.04 .10$

Тимофеев П.П., Хорольская М.В. Проектный потенциал франко-германского оборонного сотрудничества // Анализ и прогноз. Журнал ИМЭМО РАН. 2020. №4. С. 62-75. DOI: 10.20542/afij-2020-4-62-75

Щегловин Ю.Б. О целях визита президента Франции в Саудовскую Аравию. Институт Ближнего Востока. 16.11.2017. URL: http://www.iimes.ru/?p=39119 (дата обращения 13.02. 2021).

\section{References}

Béraud-Sudreau, L. (2017). La politique française de soutien à l'export de défense. Raisons et limites d'un succès [France's Arms Export Support Policy. The Reasons and Limits of Success]. Focus stratégique. 73. (In French).

\footnotetext{
${ }^{1}$ Cabirol M. Op. cit. (2021: la nouvelle année...).
} 
Gromyko, Al.A. (2019). Dilemmy Evropeiskogo oboronnogo soyuza [Dilemmas of the European Defence Union]. Kontury global'nykh transformatsii: politika, ekonomika, pravo [Outlines of Global Transformations: Politics, Economics, Law]. Vol. 12, №2. P. 6-28. (In Russian). DOI: 10.23932/2542-0240-2019-12-2-6-28

Shcheglovin, Y.B. (2017). O tselyakh vizita prezidenta Frantsii v Saudovskuyu Araviyu [The Goals of the French President's visit to Saudi Arabia]. Institut Blizhnego Vostoka [The Institute of Middle East]. November 16, 2017. Available at: http://www.iimes.ru/?p=39119 (accessed 13.02.2021). (In Russian).

Sidorov, A.S. (2019). Franko-germanskoe voenno-politicheskoe sotrudnichestvo: «Okno vozmozhnostei» ili dvizhenie po inertsii? [French-German military cooperation: «Window of opportunities» or movement by inertia?]. Aktual'nye problemy Evropy [Current Problems of Europe]. 4. P. 172-186. DOI: 10.31249/ape/2019.04.10

Timofeev P.P., Khorolskaya M.V. (2020). Proektnyi potentsial franko-germanskogo oboronnogo sotrudnichestva [Project Potential of the Franco-German Defense Cooperation]. Analiz i prognoz. Zhurnal IMEMO RAN. [Analysis and Forecasting. IMEMO Journal]. 4. P. 62-75. (In Russian). DOI: 10.20542/afij-2020-4-62-75

Zimenkov, R.I. (2018) Politika SShA v oblasti eksporta vooruzhenii [U.S. Politics in the Arms Trade]. SShA i Kanada: ekonomika, politika, kul'tura [USA \& Canada Journal]. 10. P. 21-35. (In Russian). DOI: 10.31857/S032120680001073-4

\section{The European Turn in France's Arms Export}

Author. Aleksei Chikhachev, Candidate of Political Sciences, Lecturer in Saint-Petersburg State University. Address: 7-9, Universitetskaya emb., Saint-Petersburg, Russia, 199034. E-mail: alexchikhachev@gmail.com.

Abstract. This article analyzes a new trend in the arms export policy of modern France - an increasing share of European countries in the geographical structure of sales. Based on statistics and examples, regional priorities of French export before Emmanuel Macron's presidency are identified; the reasons for the turn towards Europe at present stage and its possible limits are studied. The author draws attention to the fact that until recently, the Middle East and Asia have been key partners of France, providing two thirds of international demand for the products of French defense industry. However, today their role is declining in favor of the EU countries: Belgium, Romania, Greece, etc., with which Paris has signed a series of major contracts in 2018-2021. This development primarily stems from a difficult foreign policy context forcing the EU members to allocate more funds for defense needs, as well as from temporary difficulties in France's relations with Middle Eastern clients. The author concludes that the «Europeanization» of sales is likely to continue but it is too early to talk about a full reorientation of French exports towards Europe. A more realistic task Paris de facto solves is to balance its export structure by diversifying the range of customers.

Key words: France, European Union, Middle East, arms trade, defense cooperation, Emmanuel Macron.

DOI: http://dx.doi.org/10.15211/vestnikieran220218592 